\title{
Do they Aggress Earlier? Investigating the Effects of Ego Depletion on Police Officers' Use of Force Behavior
}

\author{
Mario S. Staller ${ }^{1,2} \cdot$ Paul Christiansen $^{1} \cdot$ Benjamin Zaiser $^{1} \cdot$ Swen Körner $^{1,2} \cdot$ Jon C. Cole $^{1}$ \\ Published online: 1 December 2017 \\ (C) The Author(s) 2017. This article is an open access publication
}

\begin{abstract}
Endowed with the state monopoly on the legitimate use of even potentially lethal force, it is intolerable for police officers to act outside the governing legal and ethical framework. At the same time, officers are expected to exert self-control and refrain from excessive use of force when they deal with provocative and perilous situations. This study sought to investigate corresponding selfcontrol and self-control failures through the role of ego depletion in the decision to use force by police officers. Two experiments were conducted using officers from a German State Police force, requiring the participants to use force against a provocative role player. Experiment 1 found that the ego depletion measure failed and there were no differences between the groups. Using a different ego depletion method, experiment 2 found that ego-depleted participants aggressed earlier than controls. These results indicate that circumstances that produce ego depletion could lead to the inappropriate use of force through reducing self-control. This has major implications for the police use of force and how we understand police officers' decision-making in response to provocation.
\end{abstract}

Keywords Ego depletion $\cdot$ Self-control $\cdot$ Police use of force $\cdot$ Aggression

\section{Introduction}

Humans are capable of inhibiting aggressive urges that are associated with negative outcomes in the long run (Finkel 2014). A co-worker, for instance, may choose to suppress affective behavior and prevent negative repercussions on the relationship with his colleagues, despite the temptation to shout at them in an emotionally intense discussion. Likewise, a football player may have a strong desire to retaliate for a foul against him but resist these urges in order to continue playing instead of being red-carded due to aggressive behavior towards another player.

In policing, Donner and Jennings (2014) demonstrated that low levels of self-control are related to police misconduct. Even in situations where the use of force may be legitimate, it has been argued that self-regulation that allows for the use of non-aggressive behaviors may prove

Mario S. Staller

mario.staller@liverpool.ac.uk

1 Tactical Decision Making Research Group, Department of Psychological Sciences, University of Liverpool, Liverpool, UK

2 Institute of Pedagogy and Philosophy, German Sports University Cologne, Cologne, Germany to be a more effective and less risky option for police officers (Zaiser and Staller 2015). Despite the ability to achieve compliance through physical force, use of force generally results in merely temporary compliance and may ultimately lead to disrespect and violence on the part of the subject (Reisig et al. 2004; Sherman 1993; Tyler and Huo 2002; Wolfe 2011). To date, research has yet to address the potential relationship between self-control failure and use of force. Klukkert et al. (2009) investigated the motivation of German police officers to use force and provided first empirical insight: in contrast with prescribed behavior that follows legal and institutional guidelines (i.e., reflecting top-down-driven behavior), the routine behavioral conflict situations of police work are often emotionally driven. The researchers concluded that "the more the officers are drawn into the whirlpool of conflicts between maintaining authority on the one and the fear of escalation on the other hand, the more their actions will be determined by emotions and the higher the probability that legal guidelines will be ignored and that a violent response will serve as a mechanism to resolve the conflict" (p. 199).

With this study, we aimed to investigate the role of selfcontrol in police officers, specifically the extent to which selfregulation failures may transfer into aggression and/or defensive behavior as displayed by the inappropriate use of force. 


\section{Self-Control and Ego Depletion}

Humans have the capacity to deliberately control impulses (Ainslie 1975; Eisenberg et al. 2003; Fujita and Han 2009) and to direct behavior towards future goals and long-term desirable outcomes (Fishbach and Labroo 2007; Logue 2010), without giving in and satisfying immediate urges and temptations (Metcalfe and Mischel 1999; Mischel et al. 1989). This ability to inhibit, override, or to otherwise circumvent responses that are motivated by short-term rewards at the expense of long-term benefits is commonly referred to as self-control (Casey 2015; Fujita 2011; Hofmann et al. 2009; Mischel et al. 1989; Reynolds and McCrea 2016; Vohs and Heatherton 2000). Despite such a capacity for self-regulation, there are numerous examples in everyday life in which self-control fails. Risky sexual behavior, overeating, drug and alcohol abuse, and aggression can exemplify consequences of a failure to regulate behavior (Baumeister et al. 1993; Denson et al. 2012; DeWall et al. 2011; Finkel et al. 2009; Quinn and Fromme 2010; Slotter et al. 2012; Stinson et al. 2008).

Research into the field of self-regulation has mainly focused on the "strength model" (or resource model) of selfcontrol (Baumeister and Heatherton 1996; Baumeister et al. 1998; Heatherton and Baumeister 1996; Vohs and Heatherton 2000). The central tenet of this theory is that self-regulation is governed by a limited capacity that allows people to control impulses and desires. Such a selfregulatory resource can be depleted or exhausted by responding to self-regulatory demands. If demands on self-control are very high and/or if demands have been satisfied over a prolonged period of time, self-regulatory resources are depleted and subsequent self-control will be impaired. This state of depleted self-control resources has been termed "ego depletion" (Baumeister et al. 1998; Muraven et al. 1998). Recent investigations have shown that exerting self-control reduces the ability to regulate behavior in a subsequent task, even when self-control tasks are different in nature, domain, or context. It was shown, for instance, that controlling the temptation to eat reduced the ability to regulate aggressive behavior when responding to negative comments by an experimenter (Stucke and Baumeister 2006). Furthermore, a study found that ego depletion resulted in increased aggressive responding after being provoked with insults (DeWall et al. 2007). In addition, Finkel et al. (2009) found that within a sample of intimate partners, ego-depleted participants were more violent in response to partner provocations than non-depleted participants. It is notable that this study also found that those whose self-regulatory resources were experimentally bolstered in a 2-week training program exhibited less inclinations to violence than those participants whose selfregulatory resources had not been boosted.
Recently, emerging findings showed that self-control is not energetically dependent as initially proposed (Dang 2016b; Kurzban 2010; Molden et al. 2012). For example, recent meta-analytic evidence (Carter and McCullough 2014; Carter et al. 2015; Hagger and Chatzisarantis 2016) does not support the proposition that self-control relies on a limited resource, when tested in laboratory settings. Likewise, a multilab preregistered replication study (Hagger and Chatzisarantis 2016) of the ego depletion effect with 23 laboratories $(N=2141)$ using a sequential task paradigm failed to replicate the ego depletion effect, providing evidence that, if there is any ego depletion effect, it is close to zero. However, a recent complimentary analysis of the data (Baumeister and Vohs 2016; Dang 2016a) suggests that the failure of Hagger's and Chatzisarantis' (2016) replication study may result from the ineffectiveness of their manipulation (e-crossing task). Analyses of the data sets, where people consider the manipulation as effortful, indicates an ego depletion effect (Baumeister and Vohs 2016; Dang 2016a).

Consequently, the need for alternative conceptualizations of a theory of self-control has been articulated. Reynolds and McCrea (2016) introduced the dual component theory of inhibition regulation, focusing on the functional aspect of selfcontrol. The model assumes that (a) it is functional to apply self-control in certain situations, in order to regulate impulsive behavior; (b) it is undesirable for self-control to be applied indefinitely; and (c) self-control varies across contexts. The model features two distinct components: a monitor and a threshold component. The former detects that the need to act impulsively needs to be inhibited, sending a signal of inhibition effort to the second component. The threshold component, in turn, processes the signal to determine whether the threshold has been crossed. Therefore, the threshold component represents the individual's tolerance for applying inhibitory effort. A central implication of the dual component theory of inhibition regulation is that inhibitory self-control is viewed as an information processing mechanism, in contrast to the view of self-control as energy in the resource model. As such, the cessation of inhibition is not automatically considered a "failure." This would be determined by context. For instance, aggressive behavior (cessation of inhibition to aggress) can be necessary for a police officer if he needs to mitigate a violent threat.

With regards to the context of policing, theories of selfcontrol provide a valuable framework for assessing aggressive behavior of police officers, specifically how contextual factors like ego depletion influence subsequent behavior concerning the use of force. Furthermore, the current discussion about controversial views on the resource model and the ego depletion effect in general could benefit from experimental paradigms aiming at further investigating the link between potential ego depletion effects and aggressive behavior. 


\section{Self-Control and Aggression}

With regards to aggressive behavior, there are only a few studies that have tested the effect of ego depletion on aggression (Barlett et al. 2016; DeWall et al. 2007; Stucke and Baumeister 2006; Vohs et al. 2011). For example, Stucke and Baumeister (2006) showed that participants were required to resist tempting food or to concentrate on a boring film, while stifling their physical and facial movements (depletion condition). Subsequently, they reacted more aggressively to an insult, responding to the insulting person with worse feedback. Likewise, Vohs et al. (2011) provided evidence that depleted participants elicited more aggressive responses than non-depleted participants, playing a game, in which unpleasant noise was directed at opponents. Ego depletion was induced by tasking participants to watch disgusting footage from two movies. The depletion group was additionally required to not show any facial expression and to neutralize their innermost feelings. The results also showed that sleep deprivation had no effect on the aggressive responses. Confirming the results of Stucke and Baumeister (2006), DeWall et al. (2007) demonstrated that aggression was highest when participants were provoked and ego-depleted. However, if participants were not insulted and the urge to aggress was relatively weak, ego depletion did not increase aggressive behavior. In a recent study, Barlett et al. (2016) tested aggression change as function of ego depletion and provocation systematically and found that aggression was highest for ego-depleted participants who were provoked. Yet, since previous studies only measured aggression indirectly (i.e., rated by the experimenter) or with non-physical forms of aggression (i.e., through noise blast or hot sauce) as well as in the absence of the recipient of the aggressive behavior, it has yet to be shown that ego depletion can also result in physical manifestations of aggression and defensive behavior.

Inhibition plays a crucial role in the display of aggression (Finkel 2007; Finkel et al. 2012). Depending on the context, a cessation of inhibition may sometimes be functional (Reynolds and McCrea 2016). In policing, the display of aggression and defensive behavior is warranted in situations of immediate threat and in situations where compliance cannot be achieved in any other way. Yet, the interpretation of "cannot be achieved in any other way" varies. As Klukkert et al. (2009) indicated, emotional cognitions centered around the fear of losing authority and the fear of escalation may trigger aggression towards initially non-compliant citizens. Though still in line with legal and institutional guidelines, exhibiting aggression too early in police-citizen encounters may impose costs for the officer at a later point, for instance through an increased risk to the officer's physical integrity following a suspect resisting arrest (Reisig et al. 2004; Sherman 1993; Tyler and Huo 2002; Wolfe 2011). The regulation of selfcontrol, especially in light of provocation, would be beneficial in order to further negotiate non-physically (Zaiser and Staller 2015). However, it is unclear if ego depletion leads to a cessation of inhibition of offensive aggression during policecitizen encounters.

\section{Present Research}

To date, only a few studies investigated the effects of loss of self-control on aggressive behavior. This sequence of studies aimed to investigate the loss of self-control of police officers as a result of ego depletion and the extent to which it produces aggressive behavior. Our primary goal was to extend the findings of previous research on self-control and aggression, which has demonstrated that ego depletion affects aggressive behavior in terms of indirect or covert forms of aggression. In this project, we asked if these findings transfer to the policing domain, where aggression occurs directly and in physical forms. Our secondary goal was to determine if depletion manipulations that have been found to work with different populations would also work with police officers, thus validating experimental paradigms for further studies on ego depletion in the policing domain.

In the current research, participants completed a use of force scenario, where they were confronted by a provocative role player. We used two different manipulation tasks that have been used in previous research in order to induce a state of ego depletion. In experiment 1 , we employed a cognitive suppression task following the watching of a video clip (Christiansen et al. 2012), whereas in experiment 2, we employed the cold pressor task (Birnie et al. 2012; McParland et al. 2016, 2013), which involves putting one's hand in very cold water and to leave the hand immersed until it is painful. The general procedure for both experiments stayed the same. Ethical approval was obtained by the ethics committee of the University of Liverpool.

\section{Experiment 1}

In experiment 1 , we assessed offensive aggression in a representative scenario setting that resembled real-world situations at an authentic level. Participants had to actually execute their decision to aggress by using force (in contrast to experimental paradigms, where participants only indicated their intentions). The ego depletion manipulation consisted of (a) watching a disgusting and objectionable video while suppressing any emotional reaction to it and (b) a thought suppression task that required participants to write down their thoughts without thinking about the video they just had seen. Both manipulations have been successfully employed in previous research with undergraduates (Christiansen et al. 2012). However, it was not clear if this manipulation would work for police officers. Therefore, a manipulation check was conducted to 
ensure the participants were ego-depleted, before they had to engage in a use of force scenario with a provocative role player. Based on the results of previous research, we hypothesized that the experimental manipulation would produce changes in the manipulation check measurements (hypothesis 1) and that ego-depleted participants would display offensive aggression earlier in the course of the scenario than nondepleted participants (hypothesis 2).

\section{Methods}

\section{Participants}

A total of 44 police officers of a German state police force participated in experiment 1. Participants were randomly assigned to either the ego depletion or control group. All participants had experience as patrol officers and were currently assigned to a police force tasked with the collection of evidence and the apprehension of suspects in criminal hot spots as well as regular patrol duties ("Beweissicherungs- und Festnahmeeinheit"). Each group consisted of 22 police officers. Descriptive statistics for the full sample and the split by condition are displayed in Table 1. Notable groups were balanced on gender, age, and experience.

\section{Materials and Procedure}

General procedures were the same for experiments 1 and 2 . They only differed in the task that was used to induce ego depletion. Testing sessions took place at a state police academy between 8 a.m. and 6 p.m. Each subject attended only one study. All participants were briefed about the study and provided their informed consent in the morning.

In experiment 1 , both participant groups watched a clip from the movie Audition (Miike 1999). The chosen section was 18-min long and edited to a final clip of $5 \mathrm{~min}$, due to numerous flashbacks with irrelevant/redundant content. The clip contained graphic depictions of torture (e.g., a foot amputation performed with a wire). This clip was used because it is easier to manipulate emotions like disgust than emotions such as happiness or sadness (Gross and Levenson 1993). It is also proven to be an effective stimuli for the experimental condition (Christiansen et al. 2012). Participants in the experimental condition were informed that they should try not to respond to the clip in any way (no facial expressions or turning away), and that they should suppress any thoughts, feelings, or emotions that they may experience while watching the clip. The control group received a similar task, but was not tasked to control behavior, thoughts, or emotions. The experimenter remained in the room throughout the task, in order to observe participants' emotional expressions and to provide task instructions if necessary. Furthermore, participants were informed that any results of the tests will be treated anonymously and that data processing and analysis will only be conducted by academic personal that is not part of the Hessian police force.

When the clip was finished, participants were required to complete a manipulation check questionnaire. They were asked to rate (a) perceived effort that they put into suppression, (b) perceived difficulty of suppression, (c) emotionality of the task, (d) feelings of being emotionally drained, as well as (e) tiredness, all on a 25-point Likert scale. Afterwards, participants completed a cognitive suppression task. Subjects in the ego depletion group were told to write down any thoughts that came to mind over the next $5 \mathrm{~min}$ but not to think about anything that they had just seen in the clip. Participants of the control group were told to write down any thoughts that they had over the following $5 \mathrm{~min}$. The film clip was not mentioned by the experimenter. Once the cognitive suppression task was completed, participants completed a second manipulation check and the Brief Mood Introspection Scale (BMIS), which is a self-report measure of mood and arousal (Mayer and Gaschke 1988). The BMIS consists of 16 adjectives that are rated on 4-point Likert scales, ranging from "definitely not feeling" (1) to "definitely feeling" (4). Four underlying mood factors are derived: pleasant-unpleasant, arousal-calm, positive-tired, and negative-relaxed. Factor scores are derived by adding or subtracting scores from relevant items. The pleasant-unpleasant factor, for instance, is computed by subtracting values for unpleasant adjectives (e.g., grouchy, sad) from scores derived from pleasant adjectives (e.g., content, happy). Cronbach's alpha for the subscales of the BMIS was computed between 0.76 and 0.83 (Mayer and Gaschke 1988).

Following the experimental manipulation, participants had to complete a scenario involving the handling of a provocative citizen played by an experienced use of force trainer. The time between finishing the experimental
Table 1 Group characteristics for experiment $1(M \pm \mathrm{SD})$

\begin{tabular}{llllc}
\hline Characteristics & Sample $(N=44)$ & Experimental $(N=22)$ & Control $(N=22)$ & $p$ value \\
\hline Gender $(\mathrm{M} / \mathrm{F})$ & $(39: 5)$ & $(19: 3)$ & $(20: 2)$ & .635 \\
Age & $27.58(3.96)$ & $28.18(4.17)$ & $26.97(3.73)$ & .919 \\
Experience & $6.15(3.49)$ & $6.51(3.87)$ & $5.79(3.12)$ & .788 \\
\hline
\end{tabular}

The $p$ value represents $t$ tests comparing age and experience and chi-square tests comparing gender 
manipulation and starting of the scenario was approximately $30 \mathrm{~s}$. The scenario was developed by experienced use of force trainers of a German state police force. Participants were required to fulfill their assignment as police officers on a routine basis. They were assigned to a fixed spot in the training environment and briefed about their assignment for the upcoming scenario training. The assignment involved a cordoned-off area behind the officer, due to an unspecified, hypothetical police operation. As soon as the scenario started, a role player presented himself at the scene. The role player followed a pre-defined script (see Table 2 and Fig. 1), involving several levels of behavior in intervals of $30 \mathrm{~s}$. The general intention of the role player was to pass through the cordoned area. Every $30 \mathrm{~s}$, the level increased in terms of provocation and threatening behavior towards the participants. Each scenario culminated in a situation where the participant had to control the role player physically to prevent him breaching the cordon. All sequences were filmed using a GoPro Hero4 camera (GoPro Inc.). The dependent variable was the time from the onset of the scenario, when the role player appeared for the first time, until the participants showed aggressive behavior for the first time. Aggression in the context of this scenario was defined as any visible behavior to physically control the role player (e.g., takedown) or to obtain control over him (e.g., closing the distance to the role player by leaving the pre-defined spot, where the area was cordoned off). The dependent variable was timed, based on the video footage of participants' performance. After the scenario exercise, participants were debriefed and thanked for their participation.

In order to ensure health and safety for participants and the role player, recommendations for balancing representative testing environments with the psycho-physiological protection of involved individuals were followed (Staller et al. 2017; Wollert et al. 2011). Therefore, role players wore a RedMan Instructor Suit, which allows for receiving full impact blows. Participants wore their personal protective equipment and were issued inert weapons. Additionally, role players were instructed to aggress according to the script, which only allows pushes and no strikes or blows.

\section{Statistical Analysis}

We performed a Shapiro-Wilk's test (Razali and Wah 2011; Shapiro and Wilk 1965) and a visual inspection of their histograms. Each data set of experiment 1 was analyzed with normal quantile-quantile plots and box plots (Doane and Seward 2011). A preliminary analysis of the manipulation check questions and the BMIS data indicated that the data set was not normally distributed. The data set

Table 2 Characteristics of suspect behavior in the scenario in experiment 1

\begin{tabular}{|c|c|c|c|c|}
\hline Level & Time (s) & Distance (m) & General behavior of role player & Examples of verbal communication by role player \\
\hline 1 & $0-30$ & 8 & $\begin{array}{l}\text { Does not talk; provocative look at the police officer; } \\
\text { does not react to any communication initiated } \\
\text { by the police officer }\end{array}$ & No verbal communication \\
\hline 2 & $30-60$ & 8 & $\begin{array}{l}\text { Wants explanation for the police measures; does not } \\
\text { relate to the police officer; has the impression that } \\
\text { measure is only to annoy him }\end{array}$ & $\begin{array}{l}\text { "What's the point here?"; "Explain yourself!"; "I only want to } \\
\text { go home"; "It's always the same with the police"; } \\
\text { "You're feeling strong with your weapon, don't you?"; } \\
\text { "You think you can do anything because of your uniform?" }\end{array}$ \\
\hline 3 & $60-90$ & 8 & $\begin{array}{l}\text { Uses personal provocations; does not react if he is } \\
\text { sent off by the police officer }\end{array}$ & $\begin{array}{l}\text { "You only want to annoy me!"; "You cops are kind of stupid"; } \\
\text { "You think I am stupid, don't you?"; "Seems like they hire } \\
\text { everybody as an police officer!"; "Standing around--that's } \\
\text { what you were made for!"; "You're provoking me!" }\end{array}$ \\
\hline 4 & $90-120$ & 5 & Shortens the distance; uses personal provocation & $\begin{array}{l}\text { See level 3; } \\
\text { Additionally: "You're a looser-you cannot do anything!" }\end{array}$ \\
\hline 5 & $120-150$ & 3 & Shortens the distance; uses personal provocation & $\begin{array}{l}\text { See levels } 3 \text { and } 4 \text {; } \\
\text { Additionally: "You are all stupid fucks!" }\end{array}$ \\
\hline 6 & $150-180$ & 3 & Maintains the distance; shouts at the police officer & $\begin{array}{l}\text { "Fuck off!"; "Take your stuff and piss off!"; "Take your } \\
\text { buddies and hit the road!"; "I help you getting your stuff!"; } \\
\text { if participant says "Calm down!", role player shouts: } \\
\text { "I am calm, you shout!" }\end{array}$ \\
\hline 7 & $180-210$ & $0-1$ & $\begin{array}{l}\text { Pushes police officer at the arm; firm voice } \\
\text { (but not shouting) }\end{array}$ & $\begin{array}{l}\text { "Get off!"; "I help you getting away from here!"; "Take } \\
\text { your buddies and hit the road!" }\end{array}$ \\
\hline 8 & $210-240$ & $0-1$ & Continues pushing police officer; shouts loudly & $\begin{array}{l}\text { "Take your stuff and fuck off!"; "Get lost!"; "Take your } \\
\text { buddies and piss off!” }\end{array}$ \\
\hline 9 & $240-270$ & $0-1$ & Pushes officer on the chest; continues shouting & See level 8 \\
\hline
\end{tabular}


Fig. 1 Levels of the interaction between the role player and police officer in the scenario in experiment 1
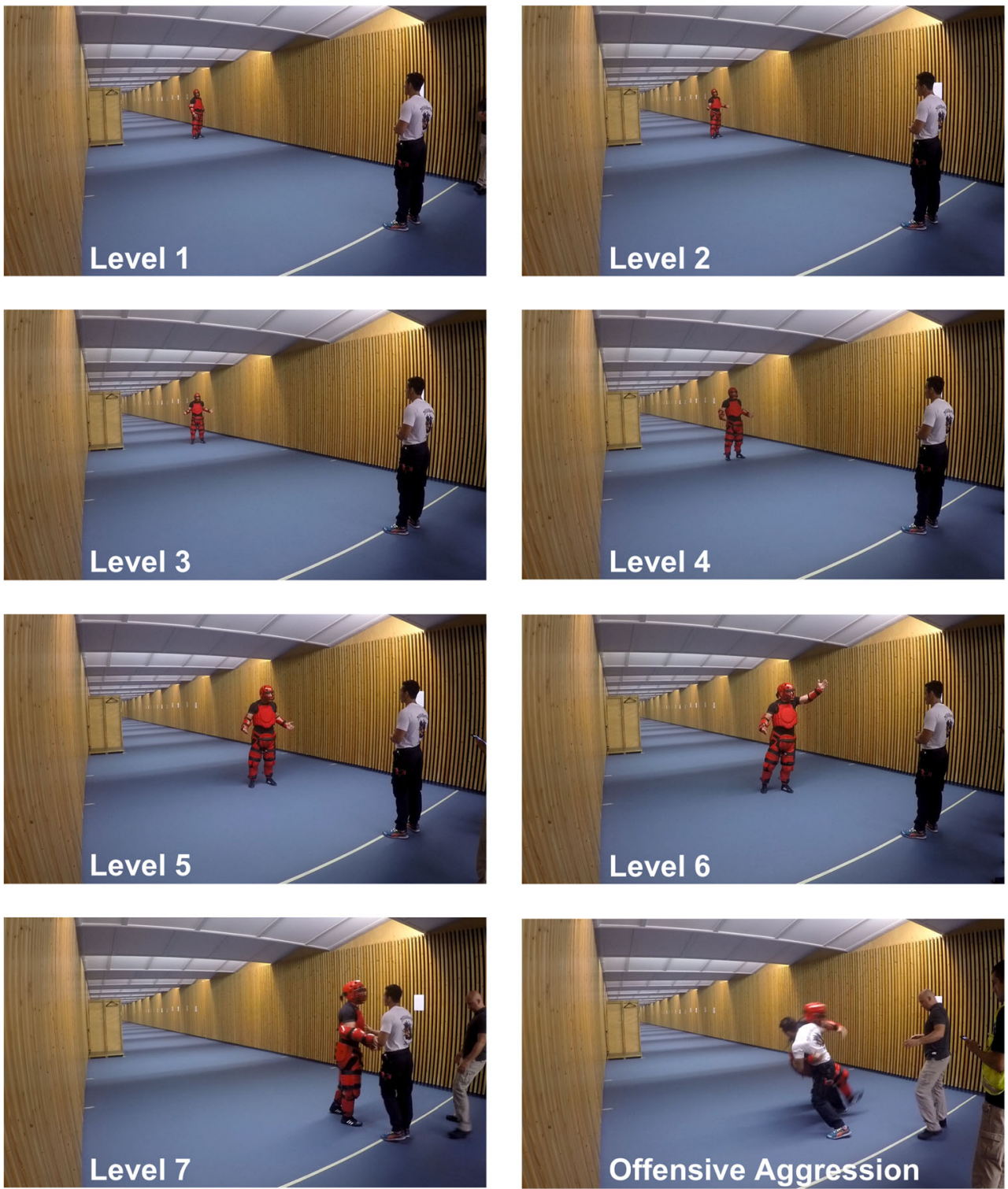

was bootstrapped to allow for robust testing (independent $t$ tests). The time until offensive aggression was exhibited by the subjects (aggression time) was also not normally distributed. Hence, we also performed bootstrapping on this data set before analyzing the data using independent $t$ tests.

\section{Results and Discussion}

In order to assess the success of the ego depletion manipulation, the manipulation check and BMIS data were analyzed using a series of independent $t$ tests. Participants reported no significant differences between an ego depletion and control condition in terms of the BMIS sub-scales and the self-reports on (a) perceived effort of emotional suppression, (b) perceived difficulty of emotional suppression, (c) emotionality of the task, (d) feelings of being emotionally drained, or (e) tiredness. Self-reports of (a) effort of suppression of thoughts, (b) difficulty of suppression of thoughts, (c) feeling emotionally drained, and (d) tiredness following the thought suppression task yielded no significant differences between the groups. This indicates that the employed manipulation did not lead to a state of ego depletion in the participants. Summary data for manipulation check and mood variables are shown in Table 3.

On average, participants in the experimental condition showed aggression towards the role player earlier $(M=$ $174.09 \mathrm{~s}, \mathrm{SE}=9.89)$ than participants in the control condition $(M=191.59 \mathrm{~s}, \mathrm{SE}=9.12)$. This difference, $-17.50 \mathrm{~s}, \mathrm{BCa}$ $95 \%$ CI $[-45.84,9.47]$, was not significant, $t(42)=-1.30$, $p=.200, d=-0.40$. Figure 2 displays means and $95 \%$ CI of that effect. 
Table 3 Group comparisons of manipulation check and mood variables of experiment 1

\begin{tabular}{|c|c|c|c|c|c|c|c|c|c|c|c|c|c|c|}
\hline \multirow[t]{3}{*}{ Variable } & \multicolumn{4}{|c|}{ Experimental $(N=22)$} & \multicolumn{4}{|c|}{ Control $(N=22)$} & \multicolumn{3}{|c|}{ Difference } & & & \\
\hline & \multirow[b]{2}{*}{$M$} & \multirow[b]{2}{*}{$\mathrm{SD}$} & \multicolumn{2}{|c|}{$95 \% \mathrm{CI}$} & \multirow[b]{2}{*}{$M$} & \multirow[b]{2}{*}{ SD } & \multicolumn{2}{|c|}{$95 \% \mathrm{CI}$} & \multirow[b]{2}{*}{$M$} & \multicolumn{2}{|c|}{$\mathrm{BCa} 95 \% \mathrm{CI}$} & \multirow[b]{2}{*}{$t(42)$} & \multirow[b]{2}{*}{$p$} & \multirow[b]{2}{*}{$d$} \\
\hline & & & LL & UL & & & LL & UL & & LL & UL & & & \\
\hline \multicolumn{15}{|l|}{ Emotional suppression } \\
\hline Effort suppressing emotions & 9.59 & 5.67 & 7.08 & 12.11 & 11.23 & 5.41 & 8.83 & 13.62 & -1.64 & -4.68 & 1.40 & -0.98 & 0.333 & -0.30 \\
\hline Difficulty suppressing emotions & 8.59 & 5.73 & 6.05 & 11.13 & 10.45 & 5.07 & 8.21 & 12.70 & -1.86 & -5.07 & 1.22 & -1.14 & 0.260 & -0.35 \\
\hline Emotionality of the clip & 13.09 & 6.80 & 10.07 & 16.11 & 14.86 & 5.87 & 12.26 & 17.47 & -1.77 & -5.50 & 2.04 & -0.93 & 0.360 & -0.29 \\
\hline Emotionally drained & 5.09 & 5.55 & 2.63 & 7.55 & 6.45 & 3.70 & 4.81 & 8.09 & -1.36 & -3.90 & 1.36 & -0.96 & 0.343 & -0.30 \\
\hline Tiredness & 4.55 & 4.54 & 2.53 & 6.56 & 4.05 & 4.58 & 2.01 & 6.08 & 0.50 & -2.17 & 3.22 & 0.36 & 0.718 & 0.11 \\
\hline \multicolumn{15}{|l|}{ Cognitive suppression } \\
\hline Effort suppressing thoughts & 7.68 & 6.45 & 4.82 & 10.54 & 5.36 & 4.03 & 3.58 & 7.15 & 2.32 & -0.80 & 5.68 & 1.14 & 0.160 & 0.35 \\
\hline Difficulty suppressing thoughts & 8.09 & 7.12 & 4.93 & 11.25 & 6.27 & 3.95 & 4.52 & 8.03 & 1.82 & -1.68 & 5.49 & 1.05 & 0.301 & 0.32 \\
\hline Emotionally drained & 5.32 & 5.30 & 2.97 & 7.67 & 4.50 & 3.53 & 2.94 & 6.06 & 0.82 & -1.87 & 3.65 & 0.60 & 0.550 & 0.19 \\
\hline Tiredness & 5.77 & 4.98 & 3.57 & 7.98 & 4.27 & 4.11 & 2.45 & 6.09 & 1.50 & -1.08 & 4.22 & 1.09 & 0.282 & 0.34 \\
\hline \multicolumn{15}{|l|}{ BMIS } \\
\hline Pleasant-unpleasant & 2.86 & 5.63 & 0.37 & 5.36 & 3.41 & 6.65 & 0.46 & 6.36 & -0.55 & -4.11 & 3.16 & 0.29 & 0.770 & 0.09 \\
\hline Arousal-calm & 15.09 & 4.82 & 12.95 & 17.23 & 15.82 & 3.79 & 14.14 & 17.50 & -0.73 & -3.11 & 1.72 & 0.56 & 0.581 & 0.17 \\
\hline Positive-tired & 6.00 & 3.48 & 4.46 & 7.54 & 6.68 & 3.70 & 5.04 & 8.32 & -0.68 & -2.71 & 1.16 & -0.63 & 0.532 & -0.19 \\
\hline Negative-relaxed & 6.64 & 3.59 & 5.04 & 8.23 & 6.86 & 2.98 & 5.54 & 8.19 & -0.23 & -2.16 & 1.77 & 0.23 & 0.820 & 0.07 \\
\hline
\end{tabular}

These findings indicate that the experimental manipulation did not work with this sample of police officers, providing a possible explanation why no significant effect between the experimental and the control condition was observed. The failing of the experimental manipulation in experiment 1 is inconsistent with previous results employing the same ego depletion manipulation. Christiansen et al. (2012) showed that emotional and cognitive suppression following the same video clip was rated

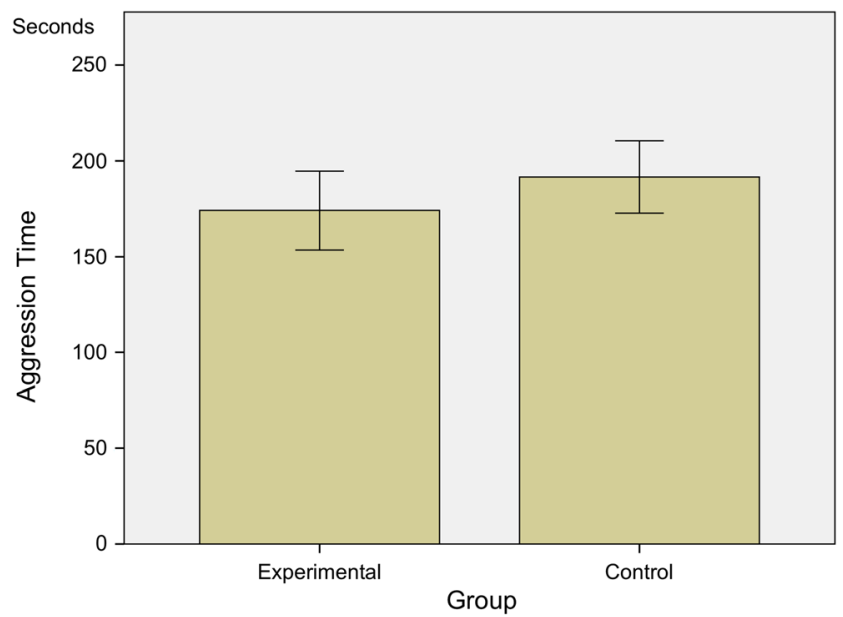

Fig. 2 Time till participants showed offensive aggression in experiment 1. Means and $95 \%$ confidence intervals are displayed in seconds more effortful and more difficult by the ego depletion group than by the control group. However, participants were normal undergraduates. In this study, the participants were law enforcement officials. Since police officers experience situations that can involve negative feelings like disgust on a regular basis, it is possible that they are used to such visual stimuli, which are known to elicit disgust in non-police individuals. Another possibility is that the police population in general consists of individuals that are less prone to feel disgust after such a video clip.

\section{Experiment 2}

Since the experimental manipulation in experiment 1 did not work with police officers, we chose another approach to assess the effects of ego depletion. The general design of experiment 1 stayed the same in experiment 2 . The only difference was the manipulation task that was employed. We chose the cold pressor task (Birnie et al. 2012; McParland et al. 2013, 2016) for the ego depletion manipulation, which involves putting one's hand in very cold water and to leave the hand immersed until it is painful. Controlling impulses is known to be a successful method of inducing a state of ego depletion in participants (Hagger et al. 2010). However, it had not been clear if this manipulation would work for police officers as well. 


\section{Methods}

\section{Participants}

A total of 37 police officers took part in experiment 2 . Participants were randomly assigned to either the experimental or the control group. One participants had to leave the experiment earlier because of operational demands reducing the final sample size to 36 . All participants had experience as patrol officers and were currently assigned to the "Beweissicherungsund Festnahmeeinheit," a police force tasked with the collection of evidence and the apprehension of suspects in criminal hot spots as well as regular patrol duties. For descriptive statistics for the final sample and split by condition, see Table 4. Notably groups were balanced on age, experience, and gender.

\section{Materials and Procedure}

The general procedure of the testing sessions stayed the same as in experiment 2 . The only difference was the manipulation itself and the manipulation check questions.

The manipulation in experiment 2 was the cold pressor task. Participants were seated next to a vessel containing cold water at $1{ }^{\circ} \mathrm{C}$ and asked to lower their non-dominant hand up to the wrist all the way down into the water. Different instructions were provided for the ego depletion and control groups. The ego depletion group was asked to keep the hand in the water as long as possible. The control group was told that they should take the hand out of the water as soon as they experience pain. The time of cold water immersion was measured for both groups in seconds with a stop watch. A 5-min limit was set to ensure the safety of the participants, which they were not aware of.

After the cold pressor task, participants were asked to complete a manipulation check questionnaire. They were asked to rate: (a) the perceived effort put into suppression and (b) the perceived difficulty of suppressing the impulse to remove their hand from the cold water. Furthermore, they were asked about (a) their feelings of being emotionally drained and (b) general tiredness on 25-point Likert scales. After the experiment, participants completed the BMIS and the subsequent scenario that was used in experiment 1 . At the end, participants were debriefed and thanked for their participation.

\section{Statistical Analysis}

For experiment 2, the analysis of the manipulation check questions and the BMIS data indicated that the data set was not normally distributed. We performed bootstrapping on the data set to allow for robust testing (independent $t$ tests) of the data. The time until participants displayed offensive aggression in the scenario was also not normally distributed. Hence, we performed bootstrapping on this data before analyzing the data set using independent $t$ tests.

\section{Results and Discussion}

In order to assess the success of the ego depletion manipulation, time of cold water immersion, manipulation check, and BMIS data were analyzed, using a series of $t$ tests on bootstrapped data. Participants in the experimental condition immersed their hand significantly longer in cold water $(M=$ $160.72, \mathrm{SE}=30.68)$ than participants of the control group $(M=34.78, \mathrm{SE}=3.45), t(34)=-4.08, p=.002, d=1.40$. Participants in the experimental condition reported significantly more difficulties in keeping their hand in the cold water $(M=16.44, \mathrm{SE}=1.41)$ than those in the control group $(M=$ $10.61, \mathrm{SE}=1.56), t(34)=2.78, p=.012, d=0.04$. Figure 3 depicts means and $95 \% \mathrm{CI}$ of self-reports of behavioral and emotional suppressing.

There was no significant effect of condition for the BMIS sub-scales, self-reports of emotionally exhaustion and general tiredness, and of the perceived effort of keeping the hand in the cold water. In sum, these results indicate that the cold pressor task induced a state of ego depletion in participants. Summary data for manipulation check and mood variables are shown in Table 5.

On average, ego-depleted police officers exhibited offensive aggression significantly earlier $(M=92.00 \mathrm{~s}, \mathrm{SE}=19.27)$ than participants in the control condition $(M=160.44 \mathrm{~s}, \mathrm{SE}=$ 15.19), $t(34)=-2.79, p=.014, d=-0.96$ The results are depicted in Fig. 4.

Taken together, the results of experiment 2 provided evidence that the cold pressor task manipulation works with the population of police officers. Furthermore, the results clearly indicate that if self-regulatory resources of officers are depleted, they will aggress earlier than if they are not depleted.
Table 4 Group characteristics for experiment $2(M \pm \mathrm{SD})$

\begin{tabular}{lllll}
\hline Characteristics & Sample $(N=36)$ & Experimental $(N=18)$ & Control $(N=18)$ & $p$ value \\
\hline Gender $(\mathrm{M} / \mathrm{F})$ & $(30: 7)$ & $(14: 4)$ & $(15: 3)$ & .674 \\
Age & $27.55(3.57)$ & $28.11(3.98)$ & $27.01(3.23)$ & .766 \\
Experience & $5.74(2.22)$ & $5.94(2.64)$ & $5.54(1.76)$ & .591 \\
\hline
\end{tabular}

The $p$ value represents $t$ tests comparing age and experience and chi-square tests comparing gender 


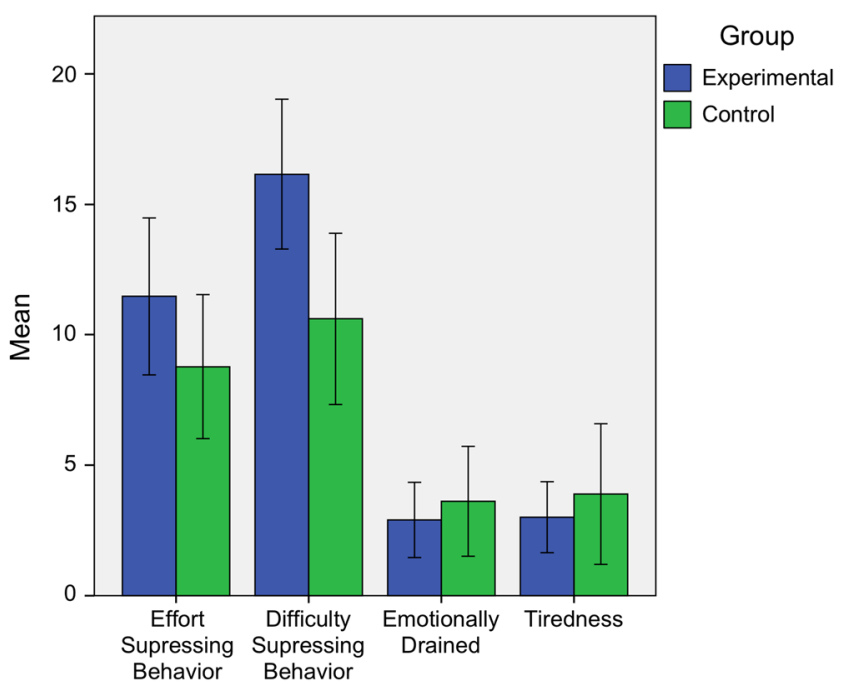

Fig. 3 Self-reports of behavioral and emotional suppressing in experiment 3 . Means and $95 \%$ confidence intervals are displayed

\section{General Discussion}

The management of aggression in the context of policing remains an important issue. While conflict can be resolved without the use of force, there will be instances that command the use of force. Then, it is expected that police officers will act within the applicable legal frameworks. In the current experiments, it was ultimately necessary to use force and therefore to be aggressive. We therefore focused on the situational parameters that can influence the decision to use force. In particular, we investigated if ego depletion in police officers influenced the decision to offensively aggress.
The experiments in the current work used two different experimental paradigms to test the hypothesis that ego depletion weakens self-control and thereby increases chances for aggressive impulses to lead to aggressive behaviors. We provided evidence that ego depletion results in earlier displays of aggressive behaviors in police officers. This finding adds to the growing body of evidence, which suggests that ego depletion affects aggressive behavior (Barlett et al. 2016; DeWall et al. 2007; Stucke and Baumeister 2006; Vohs et al. 2011). However, the current study is the first one that provides evidence that ego depletion decreases the time until physical forms of aggression occur after provoking behavior. Since there is evidence that self-control performance varies across contexts (Cohen and Lieberman 2010; Cortes et al. 2014), the current results are substantial for both the aggression literature and the police use of force domain.

The results also corroborate the recently proposed dual component theory of inhibition regulation (Reynolds and McCrea 2016). The theory suggests that there are numerous domain-specific modules working to carry out specific behaviors. Some of them are "impulsive" modules that motivate immediate behavior. According to the theory, these modules are regulated by a computational inhibition module, which comprises a monitor and a threshold component. In policecitizen encounters, the impulsive module to aggress against a provoking citizen may conflict with more long-term goals, for instance by creating later costs burdening the police-citizen relationship (Reisig et al. 2004; Sherman 1993; Tyler and Huo 2002; Wolfe 2011). The monitor module detects the requirement to inhibit an impulsive module. The "cost" or output of the impulsive module is then assessed, reflecting the temptation to aggress experienced by the police officer. A signal in

Table 5 Group comparisons of manipulation check and mood variables of experiment 2

\begin{tabular}{|c|c|c|c|c|c|c|c|c|c|c|c|c|c|c|}
\hline \multirow[t]{3}{*}{ Variable } & \multicolumn{4}{|c|}{ Experimental $(N=18)$} & \multicolumn{4}{|c|}{ Control $(N=18)$} & \multicolumn{3}{|c|}{ Difference } & & & \\
\hline & \multirow[b]{2}{*}{$M$} & \multirow[b]{2}{*}{ SD } & \multicolumn{2}{|c|}{$95 \% \mathrm{CI}$} & \multirow[b]{2}{*}{$M$} & \multirow[b]{2}{*}{$\mathrm{SD}$} & \multicolumn{2}{|c|}{$95 \% \mathrm{CI}$} & \multirow[b]{2}{*}{$M$} & \multicolumn{2}{|c|}{$\mathrm{BCa} 95 \% \mathrm{CI}$} & \multirow[b]{2}{*}{$t(34)$} & \multirow[b]{2}{*}{$p$} & \multirow[b]{2}{*}{$d$} \\
\hline & & & LL & UL & & & LL & UL & & LL & UL & & & \\
\hline Time in cold water (s) & 160.72 & 130.15 & 96.00 & 225.44 & 34.78 & 14.65 & 27.49 & 42.06 & 125.94 & 65.29 & 198.24 & 4.08 & 0.002 & 1.40 \\
\hline \multicolumn{15}{|l|}{ Behavioral suppression } \\
\hline Effort suppressing behavior & 11.28 & 6.36 & 8.12 & 14.44 & 8.78 & 5.55 & 6.02 & 11.54 & 2.50 & -1.70 & 6.65 & 1.26 & 0.217 & 0.43 \\
\hline Difficulty suppressing behavior & 16.44 & 5.99 & 13.46 & 19.42 & 10.61 & 6.60 & 7.33 & 13.89 & 5.83 & 1.84 & 9.96 & 2.78 & 0.012 & 0.95 \\
\hline \multicolumn{15}{|l|}{ Emotional suppression } \\
\hline Emotionally drained & 3.00 & 3.05 & 1.48 & 4.52 & 3.61 & 4.25 & 1.50 & 5.72 & -0.61 & -3.22 & 1.64 & -0.50 & 0.623 & -0.17 \\
\hline Tiredness & 3.11 & 2.87 & 1.69 & 4.54 & 3.89 & 5.43 & 1.19 & 6.59 & -0.78 & -4.01 & 1.84 & -0.54 & 0.595 & -0.19 \\
\hline \multicolumn{15}{|l|}{ BMIS } \\
\hline Pleasant-unpleasant & 4.72 & 7.30 & 1.09 & 8.35 & 4.78 & 3.62 & 2.98 & 6.58 & -0.06 & -3.64 & 3.64 & -0.03 & 0.977 & -0.01 \\
\hline Arousal-calm & 15.00 & 3.18 & 13.42 & 16.58 & 15.00 & 4.33 & 12.85 & 17.15 & 0.00 & -2.26 & 2.23 & 0.00 & 1.000 & 0.00 \\
\hline Positive-tired & 7.06 & 3.89 & 5.12 & 8.99 & 7.06 & 2.94 & 5.59 & 8.52 & 0.00 & -2.05 & 2.16 & 0.00 & 1.000 & 0.00 \\
\hline Negative-relaxed & 5.83 & 2.66 & 4.51 & 7.16 & 5.67 & 2.66 & 4.35 & 6.99 & 0.17 & -1.47 & 1.70 & 0.19 & 0.852 & 0.07 \\
\hline
\end{tabular}




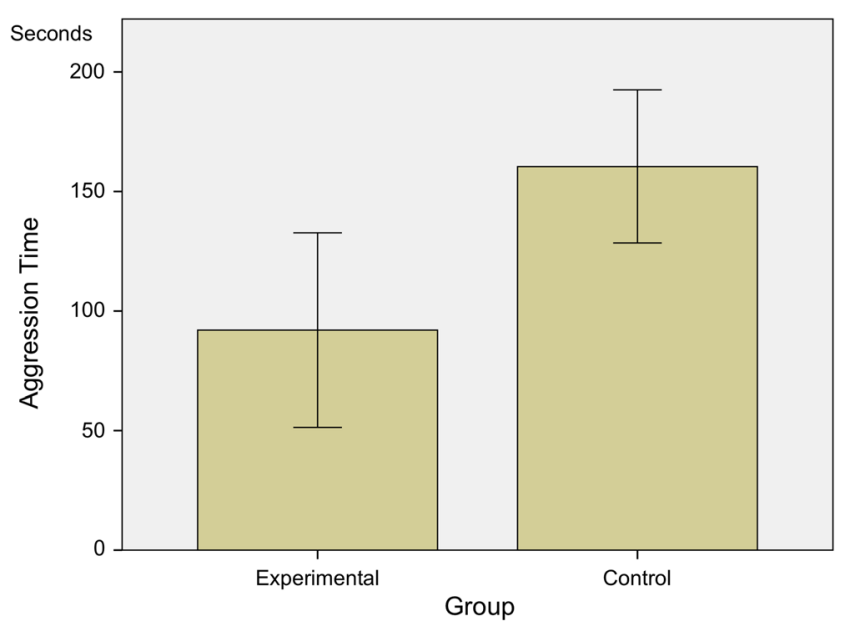

Fig. 4 Time till participants showed offensive aggression in experiment 3. Means and $95 \%$ confidence intervals are displayed in seconds

the form of an inhibition effort is produced by the monitor component and then sent to the threshold component. This signal reflects the sensation of effort that the individuals feels with inhibitory behavior. The threshold component then processes the signal of the inhibition effort to determine whether the threshold has been crossed. According to the model, this threshold represents the individual's tolerance for applying inhibitory effort. If the threshold has not been crossed, the signal is sent from the threshold component to continue to inhibit the impulsive module. With regards to the current study, non-depleted participants were able to maintain inhibitory effort in the light of provoking behavior. If the magnitude of inhibitory effort breached the limit, then the inhibition module stops inhibiting, and prepotent behavior (the impulsive module) is carried out. Therefore, the ego depletion effect of the current study reflects a reduction of the threshold for inhibition of the impulsive module to aggress.

Furthermore, the results validate theories of self-control management (Baumeister and Heatherton 1996; Reynolds and McCrea 2016; Vohs et al. 2011). After exercising selfcontrol in a first task, inhibition of impulsive responses (aggression towards a provocative citizen) becomes more difficult, as shown by earlier aggression. These observations can be explained as depleted self-control resources that lead to impulsive behavior (Baumeister 2014; Muraven and Baumeister 2000) or as problems of maintaining inhibitory effort in the face of impulsive modules that seek to carry out proponent behavior (Reynolds and McCrea 2016).

In conjunction with previous research on students (Christiansen et al. 2012), the results reported here also indicate that ego depletion manipulations are domain-specific. While students had to display inhibitory effort to suppress emotions while watching a disgusting movie clip, police officers did not. It can be assumed that regular experiences with situations, eliciting disgust, had provided the officers with coping mechanism for such situations. Future studies should consider such effects when designing experiments.

With this study, we have been able to provide a model that is capable of: (a) assessing actual aggressive behavior (and not just intentions) in the context of policing and (b) measuring self-restraint in police use of force settings. As such, for the domain of policing, we advocate using the cold pressor task in conjunction with the simulated (un)armed confrontation design, involving a scenario with role players in police use of force settings in order to capture effects of ego depletion on aggressive behavior.

\section{Practical Implications}

The current findings have several practical implications for police work. Since ego depletion may negatively affect the actual behavioral response in police-citizen encounters, it would be beneficial to focus on different strategies in order to mitigate these effects. First, the individual tolerance level can be bolstered by training (Denson et al. 2011, 2012; Miles et al. 2016). Denson et al. (2012), for instance, showed that students who practiced self-control for 2 weeks by using their non-dominant hand for everyday tasks showed reduced anger when subsequently provoked by a fictitious fellow student. Likewise, in line with the argument of training under operational constraints in order to foster skill transfer (Driskell et al. 2008; Staller et al. 2017; Wollert et al. 2011), training under ego-depleted conditions may provide the individual with the experience to cope with this internal state while displaying optimal behavior. Second, strategies aimed at reducing postdepletion aggression like mindfulness practices (Yusainy and Lawrence 2015) could be learned by police officers in order to reduce behavioral aggression following a depleting task. Third, reducing the inhibitory effort and reducing its accumulation via adapting to common self-regulatory tasks that require self-control as shown by (Dang et al. 2013) may also prove fruitful. For police officers, this would mean identifying self-regulatory tasks in their daily routine and designing programs that aim at adapting to these demands. Fourth, procedural guidelines and tactics should account for the prevention of the accumulation of inhibitory effort by changing the role of the communicating officer in a police-citizen interaction according to previous amounts of self-regulatory effort. For example, if a police officer had to suppress pain during a shift, his partner may initiate the communication in the subsequent encounter with a citizen. In the light of context specificity, future studies should focus on validating these countermeasures to the ego depletion effect for the police use of force domain. With regards to ego depletion and aggression in police use of force incidents, there are three main lines of further research that are practically relevant. First, studies could examine different ego depletion manipulations, aiming at replicating the effect with a more naturalistic demand and a higher 
ecological validity than the cold pressor task from the policing perspective. Second, studies could cover potential training procedures, which could reduce the effect of ego depletion in police-citizen encounters (Denson et al. (2011) showed, for example, that self-control training could help overcome aggressive impulses in individuals high on trait aggressiveness; it would be valuable to replicate these findings in with police officers in the current naturalistic setting). Finally, the influence of impelling factors such as trait aggressiveness on the enactment of aggression against a provocative citizen could be subject to future investigations.

\section{Limitations}

Limitations to this study stem from theoretical and methodological considerations. As for theory, the current experiments did not focus on impelling factors of aggression, such as trait aggressiveness, to determine possible interaction effects as proposed by theories of aggression (Finkel 2014). Future studies could benefit from focusing on these interaction effects in police use of force settings.

Methodological limitations include that in both experiments the intensity of the reaction was not measured. It was agreed with the police force and a premise of the current experiment that the intensity of the reaction (takedown, use of baton, gun, etc.) will not be measured. With aggression operationalized by the approach of the officer towards the suspect, future studies could investigate the reaction itself (e.g., takedown, punch, use of baton). Furthermore, along with the recent contestation of the resource depletion model and ego depletion effect discussed in the literature review above, the sequential task paradigm used in this study accounts for a limited validity of its findings. Lee et al. (2016) criticize the methodology that they found had been used in almost all ego depletion studies in two major ways: (a) the tacit assumption that individuals in the control group are sufficiently motivated to put an ego-depleting level of effort into the first task (Hagger and Chatzisarantis 2016; Lee et al. 2016; Wegner and Zanakos 1994) and (b) the neglected consideration of the duration of the first task as a moderator of the ego depletion effect (Boksem and Tops 2008; Hagger et al. 2010; Lee et al. 2016).

While these limitations may account for the absence of the ego depletion effect in experiment 1 , the use of the manipulation check questionnaire and the corresponding results imply that, based on the participants' subjective perception, ego depletion has resulted from the manipulation and ultimately led them to stress earlier.

\section{Conclusion}

With the current work, we investigated the effects of ego depletion on offensive aggression of police officers. The results indicated that ego-depleted police officers engaged in aggression earlier when provoked. Furthermore, the studies showed that the display of a disgusting video combined with the task to suppress emotions did not induce a state of ego depletion. Future studies in the context of policing should instead rely on the cold pressor task or other valid tasks in order to induce a state of depleted self-control resources. From a practical point of view, mastering self-control and reducing the effects of ego depletion seems fruitful avenues of further investigation in order to reduce aggressive behavior in police officers.

Funding This study had no funding involved.

\section{Compliance with Ethical Standards}

Conflict of Interest The authors declare that they have no competing interests.

Ethical Approval Ethical approval was granted by the Research Ethics Committee of the University of Liverpool under the reference number IPHS-1314-346.

Informed Consent Participants provided informed consent prior to the study.

Open Access This article is distributed under the terms of the Creative Commons Attribution 4.0 International License (http:// creativecommons.org/licenses/by/4.0/), which permits unrestricted use, distribution, and reproduction in any medium, provided you give appropriate credit to the original author(s) and the source, provide a link to the Creative Commons license, and indicate if changes were made.

\section{References}

Ainslie G (1975) Specious reward: a behavioral theory of impulsiveness and impulse control. Psychol Bull 82(4):463-496. https://doi.org/ 10.1037/h0076860

Barlett C, Oliphant H, Gregory W, Jones D (2016) Ego-depletion and aggressive behavior. Aggress Behav 42(6):533-541. https://doi.org/ $10.1002 / \mathrm{ab} .21648$

Baumeister RF (2014) Self-regulation, ego depletion, and inhibition. Neuropsychologia 65:313-319. https://doi.org/10.1016/j. neuropsychologia.2014.08.012

Baumeister RF, Heatherton TF (1996) Self-regulation failure: an overview. Psychol Inq 7(1):1-15. https://doi.org/10.1207/ s15327965pli0701_1

Baumeister RF, Vohs KD (2016) Misguided effort with elusive implications. Perspect Psychol Sci 11(4):574-575. https://doi.org/10.1177/ 1745691616652878

Baumeister RF, Bratslavsky E, Muraven M, Tice DM (1998) Ego depletion: is the active self a limited resource? J Pers Soc Psychol 74(5): 1252-1265. https://doi.org/10.1037/0022-3514.74.5.1252

Baumeister RF, Heatherton TF, Tice DM (1993) When ego threats lead to self-regulation failure: negative consequences of high self-esteem. J Pers Soc Psychol 64(1):141-156. https://doi.org/10.1037/00223514.64.1.141

Birnie KA, Petter M, Boerner KE, Noel M, Chambers CT (2012) Contemporary use of the cold pressor task in pediatric pain research: a systematic review of methods. J Pain 13(9):817-826. https://doi. org/10.1016/j.jpain.2012.06.005 
Boksem MAS, Tops M (2008) Mental fatigue: costs and benefits. Brain Res Rev 59(1):125-139. https://doi.org/10.1016/j.brainresrev.2008. 07.001

Carter EC, \& McCullough ME (2014) Publication bias and the limited strength model of self-control: has the evidence for ego depletion been overestimated. Frontiers in Psychology

Carter EC, Kofler LM, Forster DE (2015) A series of meta-analytic tests of the depletion effect: self-control does not seem to rely on a limited resource. J Exp Psychol Gen 144(4):796-815. https://doi.org/10. 1037/xge0000083

Casey BJ (2015) Beyond simple models of self-control to circuit-based accounts of adolescent behavior. Annu Rev Psychol 66(1):295-319. https://doi.org/10.1146/annurev-psych-010814-015156

Christiansen P, Cole JC, Field M (2012) Ego depletion increases ad-lib alcohol consumption: investigating cognitive mediators and moderators. Exp Clin Psychopharmacol 20(2):118-128. https://doi.org/10. 1037/a0026623

Cohen JR, Lieberman MD (2010) The common neural basis of exerting self-control in multiple domains. In: Hassin R, Ochsner K, Trope Y (eds) Self control in society, mind, and brain. Oxford University Press, Oxford, pp 141-161. https://doi.org/10.1093/acprof:oso/ 9780195391381.003.0008

Cortes K, Kammrath LK, Scholer AA, Peetz J (2014) Self-regulating the effortful "social dos". J Pers Soc Psychol 106(3):380-397. https:// doi.org/10.1037/a0035188

Dang J (2016a) Commentary: a multilab preregistered replication of the ego-depletion effect. Front Psychol 7:1252. https://doi.org/10.3389/ fpsyg.2016.01155

Dang J (2016b) Testing the role of glucose in self-control: a meta-analysis. Appetite 107:222-230. https://doi.org/10.1016/j.appet.2016.07. 02

Dang J, Dewitte S, Mao L, Xiao S, Shi Y (2013) Adapting to an initial self-regulatory task cancels the ego depletion effect. Conscious Cogn 22(3):816-821. https://doi.org/10.1016/j.concog.2013.05.005

Denson TF, Capper MM, Oaten M, Friese M, Schofield TP (2011) Selfcontrol training decreases aggression in response to provocation in aggressive individuals. J Res Pers 45(2):252-256. https://doi.org/10. 1016/j.jrp.2011.02.001

Denson TF, DeWall CN, Finkel EJ (2012) Self-control and aggression. Curr Dir Psychol Sci 21(1):20-25. https://doi.org/10.1177/ 0963721411429451

DeWall CN, Baumeister RF, Stillman TF, Gailliot MT (2007) Violence restrained: effects of self-regulation and its depletion on aggression. J Exp Soc Psychol 43(1):62-76. https://doi.org/10.1016/j.jesp.2005. 12.005

DeWall CN, Finkel EJ, Denson TF (2011) Self-control inhibits aggression. Soc Personal Psychol Compass 5(7):458-472. https://doi.org/ 10.1111/j.1751-9004.2011.00363.x

Doane DP, Seward LE (2011) Measuring skewness: a forgotten statistic? J Stat Educ 19(2):1-18

Donner CM, Jennings WG (2014) Low self-control and police deviance: applying Gottfredson and Hirschi's general theory to officer misconduct. Police Quarterly 17(3):203-225. https://doi.org/10.1177/ 1098611114535217

Driskell JE, Salas E, Johnston J, Wollert TN (2008) Stress exposure training: an event-based approach. In: Hancock PA, Szalma JL (eds) Performance under pressure. Ashgate, London, pp 271-286

Eisenberg N, Valiente C, Fabes RA, Smith CL, Reiser M, Shepard SA, Losoya SH, Guthrie IK, Murphy BC, Cumberland AJ (2003) The relations of effortful control and ego control to children's resiliency and social functioning. Dev Psychol 39(4):761-776. https://doi.org/ 10.1037/0012-1649.39.4.761

Finkel EJ (2007) Impelling and inhibiting forces in the perpetration of intimate partner violence. Rev Gen Psychol 11(2):193-207. https:// doi.org/10.1037/1089-2680.11.2.193
Finkel EJ (2014) The $\mathrm{I}^{3}$ model: metatheory, theory, and evidence. In: Olson JM, Zanna MP (eds) Advances in experimental social psychology, vol 49. Elsevier Inc., Amsterdam, pp 1-104. https://doi. org/10.1016/B978-0-12-800052-6.00001-9

Finkel EJ, DeWall CN, Slotter EB, McNulty JK, Pond RS, Atkins DC (2012) Using $I^{3}$ theory to clarify when dispositional aggressiveness predicts intimate partner violence perpetration. J Pers Soc Psychol 102(3):533-549. https://doi.org/10.1037/a0025651

Finkel EJ, DeWall CN, Slotter EB, Oaten M, Foshee VA (2009) Selfregulatory failure and intimate partner violence perpetration. J Pers Soc Psychol 97(3):483-499. https://doi.org/10.1037/a0015433

Fishbach A, Labroo AA (2007) Be better or be merry: how mood affects self-control. J Pers Soc Psychol 93(2):158-173. https://doi.org/10. 1037/0022-3514.93.2.158

Fujita K (2011) On conceptualizing self-control as more than the effortful inhibition of impulses. Personal Soc Psychol Rev 15(4):352-366. https://doi.org/10.1177/1088868311411165

Fujita K, Han HA (2009) Moving beyond deliberative control of impulses: the effect of construal levels on evaluative associations in self-control conflicts. Psychol Sci 20(7):799-804. https://doi.org/10. $1111 / j .1467-9280.2009 .02372 . x$

Gross JJ, Levenson RW (1993) Emotional suppression: physiology, selfreport, and expressive behavior. J Pers Soc Psychol 64(6):970-986. https://doi.org/10.1037/0022-3514.64.6.970

Hagger MS, Chatzisarantis NLD (2016) A multilab preregistered replication of the ego-depletion effect. Perspect Psychol Sci 11(4):546573. https://doi.org/10.1177/1745691616652873

Hagger MS, Wood C, Stiff C, Chatzisarantis NLD (2010) Ego depletion and the strength model of self-control: a meta-analysis. Psychol Bull 136(4):495-525. https://doi.org/10.1037/a0019486

Heatherton TF, Baumeister RF (1996) Self-regulation failure: past, present, and future. Psychol Inq 7(1):90-98. https://doi.org/10.1207/ s15327965pli0701 20

Hofmann W, Friese M, Strack F (2009) Impulse and self-control from a dual-systems perspective. Perspect Psychol Sci 4(2):162-176. https://doi.org/10.1111/j.1745-6924.2009.01116.x

Klukkert A, Ohlemacher T, Feltes T (2009). Torn between two targets: german police officers talk about the use of force. Crime Law Soc Chang 52(2):181-206. https://doi.org/10.1007/s10611-008-9178-5

Kurzban R (2010) Does the brain consume additional glucose during selfcontrol tasks? Evol Psychol 8(2):244-259. https://doi.org/10.1177/ 147470491000800208

Lee N, Chatzisarantis N, Hagger MS (2016) Adequacy of the sequentialtask paradigm in evoking ego-depletion and how to improve detection of ego-depleting phenomena. Front Psychol 7(136):1-4. https:// doi.org/10.3389/fpsyg.2016.00136

Logue AW (2010) Research on self-control: an integrating framework. Behav Brain Sci 11(04):665-679. https://doi.org/10.1017/ S0140525X00053978

Mayer JD, Gaschke YN (1988) The experience and meta-experience of mood. J Pers Soc Psychol 55(1):102-111. https://doi.org/10.1037/ 0022-3514.55.1.102

McParland JL, Knussen C, Murray J (2016) The effects of a recalled injustice on the experience of experimentally induced pain and anxiety in relation to just-world beliefs. Eur J Pain 20(9):1392-1401. https://doi.org/10.1002/ejp.862

McParland J, Knussen C, Lawrie J, Brodie E (2013) An experimental investigation of the role of perceived justice in acute pain. Eur J Pain 17(3):412-422. https://doi.org/10.1002/j.1532-2149.2012.00201.x

Metcalfe J, Mischel W (1999) A hot/cool-system analysis of delay of gratification: dynamics of willpower. Psychol Rev 106(1):3-19. https://doi.org/10.1037//0033-295X.106.1.3

Miike T (Ed) (1999) Audition. Japan

Miles E, Sheeran P, Baird H, Macdonald I, Webb TL, Harris PR (2016) Does self-control improve with practice? Evidence from a six-week 
training program. J Exp Psychol Gen 145(8):1075-1091. https://doi. org/10.1037/xge0000185

Mischel W, Shoda Y, Rodriguez MI (1989) Delay of gratification in children. Science 244(4907):933-938. https://doi.org/10.1126/ science. 2658056

Molden DC, Hui CM, Scholer AA, Meier BP, Noreen EE, D'Agostino PR, Martin V (2012) Motivational versus metabolic effects of carbohydrates on self-control. Psychol Sci 23(10):1137-1144. https:// doi.org/10.1177/0956797612439069

Muraven M, Baumeister RF (2000) Self-regulation and depletion of limited resources: does self-control resemble a muscle? Psychol Bull 126(2):247-259. https://doi.org/10.1037/0033-2909.126.2.247

Muraven M, Tice DM, Baumeister RF (1998) Self-control as a limited resource: regulatory depletion patterns. J Pers Soc Psychol 74(3): 774-789. https://doi.org/10.1037/0022-3514.74.3.774

Quinn PD, Fromme K (2010) Self-regulation as a protective factor against risky drinking and sexual behavior. Psychol Addict Behav 24(3):376-385. https://doi.org/10.1037/a0018547

Razali NM, Wah YB (2011) Power comparisons of Shapiro-Wilk, Kolmogorov-Smirnov, Lilliefors and Anderson-darling tests. J Stat Model Analyt 2(1):21-33

Reisig MD, McCluskey JD, Mastrofski SD, Terrill W (2004) Suspect disrespect toward the police. Justice Q 21(2):241-268. https://doi. org/10.1080/07418820400095801

Reynolds JJ, McCrea SM (2016) The dual component theory of inhibition regulation: a new model of self-control. New Ideas Psychol 41: 8-17. https://doi.org/10.1016/j.newideapsych.2015.12.001

Shapiro SS, Wilk MB (1965) An analysis of variance test for normality (complete samples). Biometrika 52(3-4):591-611. https://doi.org/ 10.1093/biomet/52.3-4.591

Sherman LW (1993) Defiance, deterrence, and irrelevance: a theory of the criminal sanction. J Res Crime Delinq 30(4):445-473. https://doi. org/10.1177/0022427893030004006

Slotter EB, Finkel EJ, DeWall CN, Pond RS, Lambert NM, Bodenhausen GV, Fincham FD (2012) Putting the brakes on aggression toward a romantic partner: the inhibitory influence of relationship commitment. J Pers Soc Psychol 102(2):291-305. https://doi.org/ 10.1037/a0024915

Staller MS, Zaiser B, Körner S (2017) From realism to representativeness: changing terminology to investigate effectiveness in self-defence. Martial Arts Studies (4):70-77. https://doi.org/10.18573/j.2017. 10187

Stinson JD, Becker JV, Sales BD (2008) Self-regulation and the etiology of sexual deviance: evaluating causal theory. Violence Vict 23(1): 35-51. https://doi.org/10.1891/0886-6708.23.1.35

Stucke TS, Baumeister RF (2006) Ego depletion and aggressive behavior: is the inhibition of aggression a limited resource? Eur J Soc Psychol 36(1):1-13. https://doi.org/10.1002/ejsp.285

Tyler TR, Huo YJ (2002) Trust in the law: encouraging public cooperation with the police and courts. Russell Sage, New York

Vohs KD, Heatherton TF (2000) Self-regulatory failure: a resourcedepletion approach. Psychol Sci 11(3):249-254. https://doi.org/10. 1111/1467-9280.00250

Vohs KD, Glass BD, Maddox WT, Markman AB (2011) Ego depletion is not just fatigue: evidence from a total sleep deprivation experiment. Soc Psychol Personal Sci 2(2):166-173. https://doi.org/10.1177/ 1948550610386123

Wegner DM, Zanakos S (1994) Chronic thought suppression. J Pers 62(4): 615-640. https://doi.org/10.1111/j.1467-6494.1994.tb00311.x

Wolfe SE (2011) The effect of low self-control on perceived police legitimacy. J Crim Just 39(1):67-74. https://doi.org/10.1016/j.jcrimjus. 2010.10.006

Wollert TN, Driskell JE, \& Quali J (2011) Stress exposure training guidelines: instructor guide to reality-based training. Homeland security. Retrieved from http://www.virtualtacticalacademy.com/files/stress exposure_training_manual_9-26B.pdf

Yusainy C, Lawrence C (2015) Brief mindfulness induction could reduce aggression after depletion. Conscious Cogn 33:125-134. https://doi. org/10.1016/j.concog.2014.12.008

Zaiser B, Staller MS (2015) The word is sometimes mightier than the sword: rethinking communication skills to enhance officer safety. J Law Enforcement 4(5):1-17 